\title{
Practical Occupational Medicine in "Practice"
}

\author{
Anders Ingemann Larsen ${ }^{1}$, Jan Schmidt ${ }^{2}$ and Jørgen Riis Jepsen ${ }^{2,3 *}$ \\ ${ }^{1}$ Novozymes Medical Centre, Copenhagen, Denmark \\ ${ }^{2}$ Department of Occupational Medicine, Hospital of Southwestern Jutland, Esbjerg, Denmark \\ ${ }^{3}$ Centre of Maritime Health and Society, Institute of Public Health, University of Southern Denmark, Esbjerg, Denmark
}

\begin{abstract}
In Denmark, the practice of occupational medicine tends to be carried out by specialists in occupational medicine and less so by family physicians. The provision of health service to workers is therefore limited. This constraint may also apply in other developed countries and even more in countries with few occupational health resources. This Editorial argues that family physicians are indeed in a position where they can make a major positive difference for their working patients and for the enterprises where they work. Without specialist knowledge in occupational medicine, the family physician's empiric knowledge in combination with a narrative approach to the patient permits the contribution from family medicine not only with regard to diagnosis and treatment, but also relating to actions targeted to optimize the patient's future accommodation at work as well as to protect other similarly exposed workers. Such involvement would expand the coverage of occupational health service to patients/workers on a global scale.
\end{abstract}

\section{Publication History:}

Received: December 15, 2015

Accepted: April 11, 2016

Published: April 23, 2016

\section{Keywords:}

Back-to-work, Integrated occupational medicine, Narrative medicine, Work-related disorders.

\section{Introduction}

Every day, 6,300 people die as a result of occupational accidents or work-related diseases - more than 2.3 million deaths per year 317 million accidents occur on the job annually; many of these resulting in extended absences from work. The human cost of this daily adversity is vast and the economic burden of poor occupational safety and health practices is estimated at 4 per cent of the global Gross Domestic Product each year (http://www.ilo.org/global/topics/ safety-and-health-at-work/lang--en/index.htm).

The practice of occupational medicine does not necessarily require an occupational physician, i.e. a specialist in occupational medicine. Health providers in any medical specialty, in particularly family medicine, need to regularly relate his patients' health condition to work, thereby exerting practical occupational medicine. This is evident even where clinics of occupational medicine are available.

The medical specialty occupational medicine should not be limited toepidemiological studies of physical, toxicological, ergonomic etc. exposures and their potential causal relations to a particular disease. In countries like Denmark our specialty has primarily represented such an isolated focus on etiological factors. Nor should the main focus of occupational medicine be on health examinations of workers, which is the main feature of occupational medicine in many countries world-wide where this is required by legislation or as insurance arrangements. The patients/workers need to be protected from hazards at work and to preserve their health and working capacity. Contribution to achieve this goal should be our main concern relating to health care to workers. At the same time, however, it is emphasized that workplaces share - or should share - the same wish to protect their employees so that they remain healthy and productive.

While it was previously quite common that Danish enterprises had a company doctor (mostly general practitioners with a sideline job) to advise them regarding health issues, most of them ended their practice with the advent in Denmark in the 1980s of occupational health services and hospital based clinics of occupational medicine. There was certainly a need to boost occupational medicine, but regrettably this happened at the expense of the frontline doctor. Curiously, this development occurred in Denmark while other countries with occupational health services kept medical doctors as their main core staff (as often provided by legislation on occupational health service, e.g. in the other Nordic countries). In other countries, practicing occupational physicians make a living by being available to enterprises, with which they have a consulting agreement (e.g. USA and Canada).

Although the medical community has an important role to play in this context, the transition in Denmark has in fact reduced the medical practitioners' impact on work environments and workers' health. The previous legal requirements for establishment of occupational health service in defined risk trades have been eliminated in Denmark, and currently only a handful of major industries favor from this service to workers and enterprises. What is left are consultative services that offer work environment assessments and advice to enterprises. These services, however, tend to be mostly used by enterprises with high standards and ambitions relating to their work environment, and consequently are prepared to allocate money to ensure this. Occupational health services may also be provided following an enforcement notice from the work environment authority after identification of work environment irregularities or deficiencies. The vast majority of enterprises, however, receive no such service. Furthermore, the provided occupational health services relate to technical, ergonomic,or psychological issues. They address the exposure side only and ignore the worker's health. Enterprises may well subscribe to other services such as physiotherapy and psychological care, but these services have neither a relation to occupational health and safety nor to back-to-work efforts. The lack of medical participation leaves the individual worker, let alone the vulnerable workers who are most in need, without care. Instead, the sick workers who suffer from work-related or non-work-related

*Corresponding Author: Dr. Jørgen Riis Jepsen, Department of Occupational Medicine, Hospital of Southwestern Jutland, Østergade 81-83, 6700 Esbjerg, Denmark, Tel: +45 79182285; E-mail: jorgen.riis.jepsen@rsyd.dk

Citation: Larsen Al, Schmidt J, Jepsen JR (2016) Practical Occupational Medicine in "Practice". Int J Community Fam Med 1: 106. doi: http://dx.doi. org/10.15344/ijcfm/2016/106

Copyright: (C) 2016 Larsen et al.This is an open-access article distributed under the terms of the Creative Commons Attribution License, which permits unrestricted use, distribution, and reproduction in any medium, provided the original author and source are credited. 
disorders are instead referred to hospital-based departments of occupational medicine for assessment. ThisappraisalThis appraisal may result in notification for compensation, advice about treatment and accommodation in their future work, and preventive intervention. However, most patients are seen at late stages of diseaseanddisease and the hospital departments lack the close relations to the enterprises that would facilitate individual considerations to the patients. The situation may differ from other countries but a recent survey of occupational health service in 51 countries demonstrated that the coverage was only $19 \%[1]$.

There is a need for improved occupational health care of workers and enterprises on a global scale. An increased medical input relating to the protection of workers health is particularly needed, and in our opinion this change would require an increased participation from family physicians. This Editorial aims to illustrate this new paradigm of "practical" occupational medicine and to argue for its justification.

\section{Four theses on contemporary, practical occupational medicine}

We have formulated four theses that represent what we perceive as central issues in contemporary occupational medicine (Table 1).

\begin{tabular}{|c|c|}
\hline $\begin{array}{l}\text { Thesis I } \\
\text { Work is not just something } \\
\text { dangerous - about the broad } \\
\text { context of occupational } \\
\text { medicine }\end{array}$ & $\begin{array}{l}\text { Occupational medicine is not just } \\
\text { about the "classical" monofactorial } \\
\text { occupational diseases. } \\
\text { It should be holistic and cover "all" } \\
\text { work-related factors of importance } \\
\text { for workers' health and workability }\end{array}$ \\
\hline $\begin{array}{l}\text { Thesis II } \\
\text { Evidence and the option to act }\end{array}$ & $\begin{array}{l}\text { Occupational medicine is not } \\
\text { just about epidemiological } \\
\text { evidenceofevidence of causation. } \\
\text { It should also deal with the } \\
\text { evidence extracted from the story } \\
\text { told by the patient you face or the } \\
\text { group of workers you encounter }\end{array}$ \\
\hline $\begin{array}{l}\text { Thesis III } \\
\text { Prospectively assisting the } \\
\text { patient in relation to work }\end{array}$ & $\begin{array}{l}\text { Occupational medicine is not just } \\
\text { about finding cases of occupational } \\
\text { disease. It should also provide help } \\
\text { and support to the patient in his } \\
\text { future life and work }\end{array}$ \\
\hline $\begin{array}{l}\text { Thesis IV } \\
\text { The workplace and the } \\
\text { enterprise }\end{array}$ & $\begin{array}{l}\text { Occupational medicine } \\
\text { addresses not only the patient } \\
\text { but also the workplace, the } \\
\text { working environment, and the } \\
\text { understanding and adoption in the } \\
\text { enterprises of occupational health } \\
\text { and safety }\end{array}$ \\
\hline
\end{tabular}

Table 1: Four theses on modern occupational medicine.

In the following we will elaborate on these themes with examples relevant to general practice.

\section{Work is not just a dangerous exposure- the broad context of occupational medicine}

The scope of occupational medicine should be holistic - and working life and the workplace are relevant issues (for occupational medicine) at all points where these have short or long term impact on health and well-being - not least because the workplace has a prominent place in most adult citizens' lives.
Thesis1(Table 1)states that contemporary occupational medicine is not limited to a narrow focus on the relation between a potential risk factor and a certain occupational disease. As occupational physicians we proudly recognize the results obtained from analytical etiologic research: The discovery of the relationships between lead exposure and neurological symptoms, asbestos and lung disease, noise and hearing loss, chromate exposure and contact dermatitis etc. Along with these scientific discoveries, however, important improvements of the work environments have taken place world-wide. Consequent to these changes, many classic occupational diseases have disappeared, or have become rare. And when they develop they are usually less serious than previously. There are exceptions and backlogs from past exposure, e.g. asbestos fibers continue to cause pulmonary malignancies. But generally, the classical occupational diseases are gone in the developed parts of the world, although still prevalent in developing countries with poor legislation and/or little control by authorities. Exceptions include allergic conditions for which a sufficiently reduced exposure may remain a challenge. In addition, new patterns of workrelated diseases are seen in a global context. These diseases develop consequent to new exposures or exposures of a higher intensity than previously. Examples of the latter are the increasingly frequent musculoskeletal disorders and psychosocial health impairments that are related to increased demands on productivity in order to balance wage expenses with the increased global competition.

What remains is the work itself. This can existentially and culturally be considered both a chore ("sweat of thy face") and as essential for life and family responsibilities. The work itself should, however, also constitute a positive value, which provides the daily bread, but also represents community values and contributes positively to our happiness and to form and develop our identities.

Consequently, work is a valuable feature, or at least has the potential of being valuable. Is this a statement of medical relevance? Health can be perceived as a fraction with the person's resilience as numerator, and the external loads representing the denominator. A good job - and the realization that it is good - is a positive thing. The job's value is worth retaining even though there may be hardships in the work situation. It may be easy and straightforward to spot and refer to such threats in the job. It is, however, important not to limit the focus to the challenges of the work and need less to let the existence of these challenges cause the worker to call sick and turn away from work. Obviously, the work should not be dangerous, and much improvement is still needed, but when it comes to the currently dominating work-related ailments such as mental health conditions and musculoskeletal disorders, it is also essential to address the person's ability to cope with working life even in the absence of complete health. We are not only dealing with the good work as such, but also with each individual's ability to turn the job into a good one. This issue has a clinical relevance, which is not least important when the medical practitioner is to help or empower the patient to alleviate and prevent work-related health challenges.

\section{Evidence and the options foracting}

Thesis II (Table 1) deals with evidence-issues but has also a "narrative" character. Hearing the story told by the patient, assessingtheassessing the patient thoroughly by a physical examination and scrutinizing workplace exposures and options for improvements may contribute to uncover any existing context and meaning. Based on such an analysis it may be possible to identify and take actions that can make a difference. 
In the renaissance of Danish occupational medicine around the 1970s, the practitioners of occupational medicine were run by the righteous indignation becauseworkersbecause workers were not onlyexploitedonly exploited economically butalsobut also poisoned, worn or injured. Sometimes the emotions took over and medical rationing came into the background. Obviously, this development was not sustainable for the reputation and survival of occupational medicine. Realizing this, a backlash set in. Epidemiological skills aiming to obtain evidence became now the first priority. This transition led to invaluable research; the problem was, however, that at times the evidence-based way of thinkingmovedthinking moved into the consultation room in a wrong way. Patients do not always fit the evidence,evidence; and how should the clinician deal with those who do not fit? Furthermore, the lack of evidence, e.g. for relation of a certain exposure to a certain disease, was at times interpreted as the presence of evidence for the opposite, e.g. that such relation did not exist. In a previous debate[2] we highlighted the mindset where the patient's history in its content as well as in its narrative adds value in itself, and is not limited to constitute a source to be tested against the criteria of evidence.

Any medical practitioner will know this and in fact this recognition is the family physician's core competency. It is an old truth that the patient will tell you what is wrong if you provide the sufficient time and space to do so. The professional health care provider can then deal with the consequences and implications of this assessment.

Narrative medicine[3,4]is based on a clinical approach based on hermeneutics (Greek: hermeneutics = art of interpretation). In a hermeneutic context, understanding is achieved and truth is approached through understanding, insight, interpretation, and correction in a circular process. This process can be viewed in two universes: In one universe, the patient will experience his/her own history, which is developed through and while the story is being told; in the second universe, the health care provider - as long as the door between the two universes is open - will hear the patient's history. The combination of the patient's history with the medical practitioner's expertise permits the latter to retell a revised version of relevance for the disease and the patient's situation. The open door permits the patient and the physician to share the core of the story, which is of relevance for the relationship in between them and thus creates the basis for mutual action.

One of the authors of this article found in a file drawer in the labor inspectorate an old letter from a general practitioner, who described how he, after listening to his patient's descriptions of acute workrelated central nervous system intoxication symptoms, decided to visit the patient's workplace. He witnessed a significant exposure to vapors from organic solvents and additionally felt the neurotoxic effects of this exposure on his own body. He wrote to the work environment authority in order to share his worries and to have the authority to react. This correspondence took place years before the current focus on and awareness of the potential dangers by neurotoxic organic solvents; but the case history and his verification was sufficient evidence for the practitioner to ask the authority to intervene.

\section{Prospectively assisting the patient in relation to the work}

Thesis III (Table 1) has as its main starting point the fact that the work-related diseases that we now face, not least in primary care, are only rarely explained as a caused by one specific exposure factor. refine the diagnostics and offer the options needed to constructively

The patient's symptoms - mental or physical - are rather the consequence of the effects of multiple factors. Some of these factors may still constitute an actual exposure to the patient. Others may have previously affected the patient. Some may be exposures that can be either harmful or beneficial, while others may be of a genetic character or represent individual vulnerability or strength. Some factors may be related to work, others not. It is evident that they may either have a negative impactorimpact or promote health. Hence, it makes little sense to designate "the" responsible explanatory factor.

The patient who consults the health care provider with a health problem does not always realize this complexity; even doctors would probably have difficulties if they experienced a potentially harmful exposure that could threaten or impair their health. But in order to help the patient the health care provider needs to look at the whole range of determinants for disease and to understand which of these determinants can and should be addressed. The aim is not limited to manage the condition the best possible way so that the patient becomes well again or at least that his condition improves. It is also crucial that the patient can continue to actively function occupationally. Overall, it is essential to help and treat the patient so that the specific knowledge about the impact of the working environment is coordinated with the actual or future medical treatment and rehabilitation - even if the latter take place in another context.

As described in our first thesis,workplacethesis, workplace exposures and the requirementstorequirements to theworkersthe workers' productivityhaveproductivity have the potential to cause disease. Theycan also contribute to promote health and maintain work capacity. For example, there is good evidence that a person's risk of developing musculoskeletal disorders is increased by inappropriate ergonomic conditions (such as repetitive work), but at timesthetimes the risk can also be reduced by helping employees to stay fit [5]. For sports physicians it is a truism that one should be fit to play sports, but in occupational medicine we have tended to ratherfocusrather focus on the hazards of work. Even a person who already has locomotorlocomotors symptoms may - depending on the character of the condition -benefit from training, which may at times constitute a cornerstone in the treatment. MotivatingtheMotivating the patient to stay activemayactive may reduce the focus on the sins of the past and encourage to rather lookatlook at what may prospectively be helpful.

With a main focus on etiology and sometimes preventive intervention, hospitaldepartmentshospital departments of occupational medicine are unfortunatelynotunfortunately not always well geared to specifically help patients in this context. The shortcomingswithshortcomings with regard to rehabilitation of patients so that their work can be resumed are not limited to be a matter of physical training, which any therapist can stand for. A comprehensive rehabilitation plan requires familiaritywithfamiliarity with the work that the patient is to be eventually engaged in, and to recognizeappropriaterecognize appropriate training as a part of the plan. We can only encourage medical practitionersto emphasize that the most important target should be to get the patient back to work. This applies whether the patient is referred to the hospital department of occupational medicine or is taken care of in the primary health sector. Evidently, the prospectsshouldprospects should not be limited to a meticulous mapping out of the amount of kilograms and the way in which the patient has lifted over the years, with the potential perspective that the case could becompensatedbe compensated by insurance. Such informationmayinformation may be crucial for the insurance's case, and may also havesignificancehave significance for

Int J Community Fam Med
IJCFM, an open access journal Volume 1. 2016. 106 
the patient although the compensations are usually limited. The most important target for the patient, however, is to remain active and working, and continued work should take into account the character of the disorder and the considerations about accommodation issues at work that may be required.

\section{The workplace and the enterprise}

Regarding Thesis IV (Table 1), we emphasize that not only the individual patient, but also the work environment, the workplace and the enterprise can benefit from actions by a health provider with a mindset characterized by the approach of contemporary occupational medicine. The enterprises should be included in the scope of the medical community because they are legal partners, and because health providers can help them to create better working environments, support the accommodation of their sick or injured workers, and promote the future health of all their employees.

How then can the family doctor be useful to and provide assistance to enterprises? First of all, he can visit workplaces where his patients work. He can meet his patients at work and by being available try to inspire for correction of any pending challenge or problem at the work site. He may note that an insufficient extraction of allergenic substances explains his patients' airways symptoms, ornoteor note ergonomically poorly designed workplaces causing upper limb disorders among his patients. Workplace visits that are justified by rehabilitation or "backto-work" issues can result in advising temporary relief for the patient to cope with work (rather than just sick leave) and agreement with the management about the next steps to take.

The family doctor may also be available for the enterprise staff responsible for the work environment, when the work placesareplaces are to be assessed and preventive interventions are to be prioritized, e.g. by contributing to a discussion of exposures and health effects such as the amount of tasks or the speed of the conveyer on one side and the health effects such as stress or shoulder pain on the other side, in order to achieve a better balance between the two.

Taking into account that health remains unevenly distributed even in well-organized and wealthy societies, the family doctor may even participate in efforts extending beyond the working environment and look at other initiatives such as health promotion at work. The issue of keeping workers active and productive is important for the individual as well as for enterprises, which need productive and therefore healthy labor. Finally, the family doctor can be a consultant for the enterprise regarding advice to traveling employees, actions in case of epidemics etc.

\section{The family doctor as a practical occupational physician}

With a strategic focus, the hospital-based departments of occupational medicine could increase their activities in relation to work sites. We still see room for company doctors. There is also a need of practitioners of family medicine who act in the context of occupational medicine. Family doctors have already a substantial interaction with the workplace by certifying sick leave and providing statements relating to accommodation at work taking into account the character of tasks that the patient can or cannot perform without the risk of further health deterioration. The experiences of family doctors can further provide benefit to workplaces. Participation in discussions at the workplace with relevant persons (supervisor, union representative, etc.) about specific activities that would facilitate the return-to-work of a worker on sick leave would make it clear for all attendees what the problem is about, how it can be addressed, and ensure that agreements can be kept.

We acknowledge that general practitioners are under time-pressure, but thesuggestedthe suggested angles of occupational health might represent pleasant breaks in their work and provide invaluable benefit to patients as well as to enterprises concerned. A public primary health service would probably facilitate an occupational health engagement for the family doctor while there may be challenges relating to compensation for the occupational health services to enterprises in countries with private primary health care. We think, however, that enterprises that realize the value of occupational health services would be prepardprepared to pay for them like they pay for other business support.

Some family doctors may doubt that they are able to contribute with useful support to the workplace. Our impression, however, is that taking a tour around in the production areas and having a roundtable discussion with management and employees on health and work can in itself be of value. It can make a positive difference for the company, for the workers, and also for the doctor - provided that all participants communicate frankly and open minded. In contrast, it is less useful if the doctor holds an arrogant position where he alone knows the truth, or if the company management goes into a defensive position.

Expanding occupational health service is not only a matter for developed countries but even more so for developing countries that bear the main burden of neglect [6]. We have demonstrated that enterprises in Dar es Salaam do request occupational health servicestoservices to be provided from an established curative services with adequate professional qualifications[7]. However,aHowever, a recent review addressing other southern African countries has demonstrated a major need of capacitatingprimarycapacitating primary health service with basic occupational health knowledge in order to bridge skills deficit for delivering occupational health service [8]. More developed countries such as Iran have successfully implemented occupational health services that are integrated in the provision of primary health care, which also covers most rural areas, although there is still a need of establishing a policy for collaboration, training, and improved quality of the services [9].

Our thoughts are in line with the recommendations from the "Declaration of Alma-Ata", which recommends primary health services to address workers health(http://www.who.int/publications/ almaata_declaration_en.pdf),and later appeals from the "Global Strategy on Occupational Health for All” by WHO(http://www.who. int/occupational_health/publications/globstrategy/en/),the Seoul Statement on the "Development of Occupational Health Services for All" by the International Commission on Occupational Health (http://www.icoh2015.org/eng/pop/ICOH2015_Seoul_Statement. pdf), and recently in 2012by the Cancun "Charter on Occupation Health for All”in 2012(http://www.icohweb.org/site/multimedia/ core_documents/pdf/Cancun\%20Charter\%20on\%20Occupation\%20 Health\%20for\%20All.pdf).

\section{Competing Interests}

The authors declare that they have no competing interests.

\section{Author Contributions}

All three authors have equally participated in the preparation of this manuscript and approved the final version. 
Citation: Larsen AI, Schmidt J, Jepsen JR (2016) Practical Occupational Medicine in "Practice". Int J Community Fam Med 1: 106. doi: http://dx.doi.org/10.15344/ ijcfm/2016/106

\section{References}

1. Rantanen J, Lehtinen S, lavicoli S (2013) Occupational health services in selected International Commission on Occupational Health $(\mathrm{ICOH})$ member countries. Scand J Work Environ Health 39: 212-216.

2. Larsen Al, Jepsen JR (2002) Evidence in occupational medicine. Scand J Work Environ Health 28: 358-359.

3. Hunter KM (1996) Narrative, literature, and the clinical exercise of practical reason. J Med Philos 21: 303-320.

4. Greenhalgh T, Hurwitz B (1999) Narrative based medicine: why study narrative? BMJ 318: 48-50.

5. Mortensen P, Larsen Al1, Zebis MK2, Pedersen MT3, Sjøgaard G4, et al (2014) Lasting effects of workplace strength training for neck/shoulder/arm pain among laboratory technicians: natural experiment with 3-year followup. Biomed Res Int 2014: 845851.

6. Ahasan MR, Partanen T (2001) Occupational health and safety in the least developed countries--a simple case of neglect. J Epidemiol 11: 74-80.

7. Kayumba AV, Mlingi LB, Wilson L, Jepsen JR, Limborg HJ, et al (2006) Integrated Occupational Health Service. A survey of needs in Dar es Salaam, Tanzania. Afr Newslett Occup Health Safety 16: 62-66.

8. Moyo D, Zungu M, Kgalamono S3, Mwila CD4 (2015) Review of Occupational Health and Safety Organization in Expanding Economies: The Case of Southern Africa. Ann Glob Health 81: 495-502.

9. Rafiei M, Ezzatian R, Farshad A, Sokooti M, Tabibi R, et al. (2015) Occupational Health Services Integrated in Primary Health Care in Iran. Ann Glob Health 81: 561-567. 